\title{
Buckling of Joined Composite Conical Shells Using Shear Deformation Theory under Axial Compression
}

\author{
Mohammad Hadi Izadi - Shahrokh Hosseini Hashemi* - Moharam Habibnejad Korayem \\ Iran University of Science and Technology, Department of Mechanical Engineering, Iran
}

\begin{abstract}
This paper investigates critical buckling loads in joined conical shells under axial compression. An analytical approach has been applied to study classical linear buckling of joined cones that are made of cross-ply fiber reinforced laminates. The governing equations have been extracted using first-order shear deformation theory (FSDT), and an analytical solution has been applied to extract critical buckling loads. Accordingly, the system of partial differential equations has been solved via separation of variables using Fourier expansion and power series method. The effects of the number of layers, lamination sequences, semi-vertex angles, shell thicknesses, shell lengths and boundary conditions on the stability of joined cones have been examined. For validation, the specific examples of present study have been compared to previous studies. Using ABAQUSE/CAE software (a FEM-based software), the results of finite element have been extracted. The present method is in good agreement with the finite element and other research results. Finally, the differences of classical shell theory (CST) of Donnell type and firstorder shear deformation theory have been discussed for different shell thicknesses.

Keywords: buckling, joined laminated conical shell, first-order shear deformation, power series

Highlights
- The effect of shear deformation on the buckling of joined cross-ply laminated conical shells has been theoretically
investigated.
- The usage of two joined conical shells instead of a single cone has been discussed.
- The critical buckling loads have been evaluated for various parameters of joined cones.
- The differences between FEM and analytical solution results have been expressed.
- The differences between CST and FSDT have been discussed for different shell thicknesses.
\end{abstract}

\section{INTRODUCTION}

Conical shells are structures with a broad spectrum of applications in many contexts including hydrocarbon storage tanks, refinery structures, cooling towers, body and interface of missiles, hull of aircrafts, nozzle of missiles and jet engines, liquid transmission pipelines and tankers, power plant structures, turbines and pressurized vessels, hull of submarines and various types of constructional structures and silos. In general, the strength of a shell highly depends on its form rather than its mass, so that the best structural result can be obtained by using minimal amounts of material. This high load-bearing capacity of shells has made them particularly useful.

In 1993, Leissa [1] compiled the proposed methods for analysing free vibration of isotropic conical shells under different boundary conditions. Tani and Yamaki [2] examined elastic stability of conical shells with simple and pinned supports under axial load. Regarding power series method, Tong [3] and [4] presented an exact solution method for the free vibration of thin and thick conical shells. Wu and Chiu [5] analysed the dynamic stability of composite conical shells under time-variable loading using the perturbation theory. Using DSC method, Civalek [6] and Civalek and Ülker [7] studied free vibrations of circular panels and thin shells and compared their analytic results to experimental tests. Wisvantan et al. [8] studied the application of function approximation technique and spline method for analysing layered cylindrical and conical shells with variable thickness. They further studied vibrations of symmetric and asymmetric composite shells using the first-order shear deformation theory. The stability of functionally graded truncated conical shells under a periodic impulsive loading, non-uniform lateral pressure and combined loads was investigated by Sofiyev [9] and Sofiyev et al. [10] and [11]. The buckling of axially compressed conical and stiffened conical shells was studied by Spagnoli [12] and [13]. Ross et al. [14] and [15] studied inelastic and plastic buckling of thickwalled and ring-stiffened conical shells under external hydrostatic pressure.

Numerous papers have been proposed on the analysis of shells and plates. However, most of the previously cited studies were focused on the analysis of plates and cylindrical, spherical, and conical shells, with fewer resources available on joined shells. In their initial research works, $\mathrm{Hu}$ and Raney [16] 
followed an experimental and analytical approach using finite element method (FEM) and modal test to determine mode shapes and natural frequencies of a joined cylinder-cone set. Rose et al. [17] analysed elastic wave function in a joined cylindrical-conicalcylindrical shell. Irie et al. [18] used a transformation matrix method to analyse free vibrations of joined conical-cylindrical shells. Tavakoli and Singh [19] utilized the space of state to present an Eigenvalue solution for joined shells. Flores and Godoy [20] studied post-buckling behaviour of conical-cylindrical and cylindrical-spherical shells. Performing different types of research, researchers [21] to [24] investigated the effects of axial, local, and concentrated loading on buckling and post-buckling behaviour of isotropic joined conical and cylindrical shells. They further analysed reinforced conical-cylindrical shells and studied the influence of reinforcement rings on buckling. Benjeddou [25] used Love's approximation theory for classic shells and considered finiteelement strip elements to analyse joined conicalcylindrical shells. Dynamic instability of joined conical-cylindrical shells under periodic loading was examined via FEM by Kamat et al. [26]. Zhao [27] investigated, both theoretically and experimentally, the buckling of joined reinforced cylindrical and conical shells under internal compressive loading and particularly considered the effect of reinforcing rings.

Moreover, Caresta and Kessissoglou [28] studied the vibratory characteristics of joined isotropic conical and cylindrical shells; comparing Donnell's and Flügge's methods while employing power series method, they investigated free vibrations of the shells. They used FEM to verify their work. Niloufari et al. [29] investigated the effect of weld on buckling of joined conical-cylindrical shells. Among the latest research works on joined shells, one may refer to the analysis of free and forced vibrations of joined thin cylindrical-conical shells under various boundary conditions using Ritz-Fourier method by $\mathrm{Ma}$ et al. [30]. The linear and non-linear elastic buckling response of the conical panel is studied for a wide range of shell and stiffening parameters by means of an appropriate finite element model by Spagnoli and Chryssanthopoulos [31].

Many other research studies have been performed to present a finite element solution of shells. RezaieePajand et al. [32] to [34] develop a mixed interpolated formulation for nonlinear analysis of plates and shells using equivalent single layer (ESL) theory. They presented two triangular shell element having three and six nodes for geometrically nonlinear analysis of thin and thick shell structures. Also, they proposed a geometrically nonlinear formulation for a sixnode triangular shell element. Bucalem and Bathe [35] presented two mixed-interpolated general finite element methods for nonlinear analysis of a 9-node element and a 16-node element. Also, a formulation of general shell elements using mixed interpolation of tonsorial components is discussed by Bathe and Dvorkin [36]. Petrolo and Carrera [37] and Li et al. [38] present a novel methodology to construct refined finite shell elements. An adaptable two-level mathematical refinement approach was proposed for refined curvilinear finite shell elements based on Carrera unified formulation (CUF). Schuß et al. [39] formulate a methodology to enforce interface conditions preserving higher-order continuity across the interface using isogeometric methods (IGA).

Considering the review of related previous research studies thus far, the stability analysis of joined conical shells under axial compression was studied using classical shell theory of Donnell type by Kouchakzadeh and Shakouri [40] and [41] and Shakouri and Kouchakzadeh [42]. Also, they presented an analytical solution for axisymmetric joined conical shells under axial compression and analysed free vibrations of cross-ply joined conical shells. They did not consider the effect of shear deformation on critical buckling loads and natural frequencies.

Furthermore, Shadmehri et al. [43] and [44] presented a first-order shear deformation shell theory to study buckling behaviour of a single composite conical and cylindrical shell. They used Ritz method and Levy type solution to study buckling under axial and bending loads. Sarkhail et al. [45] and [46] studied the free vibrations of a shell made of $n$ cone segments joined together. Their governing equations were obtained by applying the classic Sanders type shell theory. Also, the shells were made from a linearly elastic isotropic homogeneous material. In the latest research studies, Izadi et al. [47] investigated analytical and FEM solutions on free vibration of joined cross-ply laminated conical shells using firstorder shear deformation shell theory.

The literature survey reveals a clear indication that the studies on the joined shells are very few in numbers. Most of these research studies were about joined cylindrical-conical shells and limited to thin shells. Also, the used shell materials are frequently an elastic isotropic homogeneous material.

The goal of the present study is to investigate the buckling specifications of a joined conical shell under axial compression, considering the effects of shear deformation. Also, the conical shells are made from fibre-reinforced laminates. Hence, first- 
order shear deformation theory is used to extract governing equations of two joined conical shells. An analytical solution based on Fourier expansion along the circumferential direction and power series method along the meridian direction is developed to separate variables of equilibrium equations and establish a system of eigenvalue problems. The continuity and boundary conditions are also applied to extract eigenvalues and examine the critical buckling loads of joined cones. The influences of the number of layers, lamination sequences, semi-vertex angles, shell thicknesses, shell lengths and boundary conditions on buckling load are examined as parametric studies.

\section{METHODS}

The coordinate system for two conical shells can be observed in Fig. 1. On this basis and first-order shear deformation theory FSDT, the displacement field for each conical shell is defined as follows:

$$
\begin{aligned}
& u(s, \theta, z)=U(s, \theta)+z \beta_{s}(s, \theta), \\
& v(s, \theta, z)=V(s, \theta)+z \beta_{\theta}(s, \theta), \\
& w(s, \theta, z)=W(s, \theta),
\end{aligned}
$$

where $U, V$, and $W$ refer to displacements of the middle surface along $s$-axis, $\theta$-axis, and normal to the surface, respectively, and $\beta_{s}$ and $\beta_{\theta}$ denote rotation changes of normal vector to middle surface around $\theta$ and $s$-axes, respectively.

It should be mentioned that all relations are expressed for a single conical shell. The 1 and 2 indices in all parameters of Fig. 1 are referred to as the first and second cone, respectively. Furthermore, using FSDT, strain-displacement relationships for a single conical shell can be written as follows [44]:

$$
\begin{aligned}
& \varepsilon_{s}=\varepsilon_{s}^{0}+z \kappa_{s}, \quad \varepsilon_{\theta}=\varepsilon_{\theta}^{0}+z \kappa_{\theta}, \\
& \gamma_{s \theta}=\gamma_{s \theta}^{0}+z \kappa_{s \theta}, \gamma_{s z}=\gamma_{s z}^{0}, \gamma_{\theta z}=\gamma_{\theta z}^{0},
\end{aligned}
$$

where

$$
\begin{aligned}
& \varepsilon_{s}^{0}=\frac{\partial U}{\partial x}, \kappa_{s}=\frac{\partial \beta_{s}}{\partial s}, \gamma_{s z}^{0}=\beta_{s}+\frac{\partial W}{\partial s} \\
& \varepsilon_{\theta}^{0}=\frac{1}{R(s)}\left(U \sin \alpha+W \cos \alpha+\frac{\partial V}{\partial \theta}\right) \\
& \gamma_{s \theta}^{0}=\frac{1}{R(s)}\left(\frac{\partial U}{\partial \theta}-V \sin \alpha\right)+\frac{\partial V}{\partial s} \\
& \kappa_{\theta}=\frac{1}{R(s)}\left(\beta_{s} \sin \alpha+\frac{\partial \beta_{\theta}}{\partial \theta}\right) \\
& \kappa_{s \theta}=\frac{1}{R(s)}\left(\frac{\partial \beta_{s}}{\partial \theta}-\beta_{\theta} \sin \alpha\right)+\frac{\partial \beta_{\theta}}{\partial s} \\
& \gamma_{\theta z}^{0}=\frac{1}{R(s)}\left(\frac{\partial W}{\partial \theta}-V \cos \alpha\right)+\beta_{\theta}
\end{aligned}
$$

In which $\varepsilon_{s}, \varepsilon_{\theta}, \gamma_{s \theta}, \gamma_{s z}$ and $\gamma_{\theta z}$ represent the strains of each point of the shell. Also, $\varepsilon_{s}^{0}, \varepsilon_{\theta}^{0}, \gamma_{s \theta}^{0}, \gamma_{s z}^{0}$ and $\gamma_{\theta z}^{0}$ are the strains of the middle surface of shell and $\kappa_{s}, \kappa_{\theta}$ and $\kappa_{s \theta}$ are the curvatures of the middle surface of shell. In addition, $R(s)$ is the curvature radius of each point on the conical shell and can be expressed as follows:

$$
R(s)=R_{0}+s \sin \alpha .
$$

Below is the stress-strain relationship for the cross-ply joined composite conical shell [48]

$$
\begin{aligned}
& \left\{\begin{array}{l}
N \\
M
\end{array}\right\}=\left[\begin{array}{ll}
{[A]} & {[B]} \\
{[B]} & {[D]}
\end{array}\right]\left\{\begin{array}{l}
\varepsilon \\
\kappa
\end{array}\right\}, \\
& \left\{\begin{array}{l}
Q_{\theta \theta} \\
Q_{s s}
\end{array}\right\}=K_{s}\left[\begin{array}{cc}
A_{44} & 0 \\
0 & A_{55}
\end{array}\right]\left\{\begin{array}{l}
\gamma_{\theta z}^{0} \\
\gamma_{s z}^{0}
\end{array}\right\},
\end{aligned}
$$

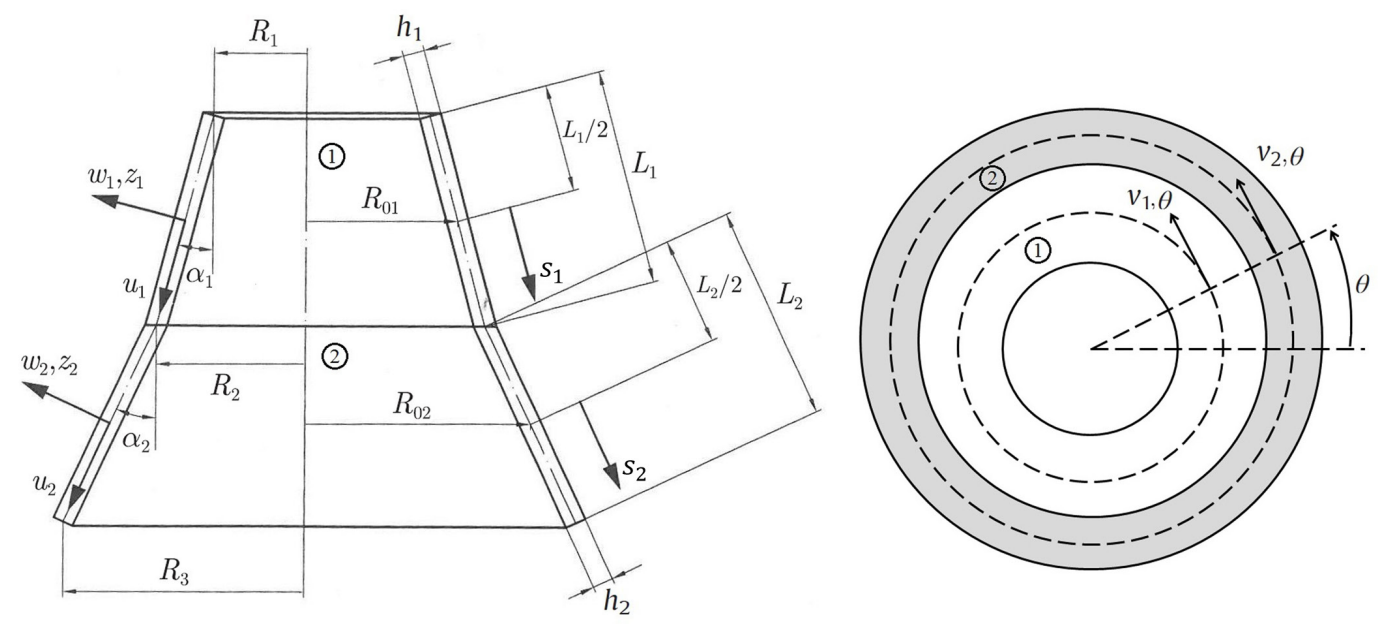

Fig. 1. Coordinate systems of two joined conical shells 
where $N$ and $M$ are the force and moment resultants, which are expressed:

$$
\left\{\begin{array}{l}
N \\
M
\end{array}\right\}=\int_{-h / 2}^{h / 2}\left\{\begin{array}{l}
\sigma \\
z \sigma
\end{array}\right\} d z
$$

moreover,

$$
\begin{aligned}
& A_{i j}=\sum_{k=1}^{N_{L}}\left(\bar{Q}_{i j}\right)_{k}\left(z_{k+1}-z_{k}\right), \\
& B_{i j}=\frac{1}{2} \sum_{k=1}^{N_{L}}\left(\bar{Q}_{i j}\right)_{k}\left(z_{k+1}^{2}-z_{k}^{2}\right), \\
& D_{i j}=\frac{1}{3} \sum_{k=1}^{N_{L}}\left(\bar{Q}_{i j}\right)_{k}\left(z_{k+1}^{3}-z_{k}^{3}\right),
\end{aligned}
$$

in which $k$ represents the $k^{\text {th }}$ layer of laminated shell, and $A_{i j}, B_{i j}$ and $D_{i j}$ are the laminated stiffness coefficients.

$$
\begin{aligned}
& \bar{Q}_{11}=Q_{11} \cos ^{4} \varphi+Q_{22} \sin ^{4} \varphi, \\
& \bar{Q}_{12}=Q_{12}\left(\cos ^{4} \varphi+\sin ^{4} \varphi\right), \\
& \bar{Q}_{22}=Q_{11} \sin ^{4} \varphi+Q_{22} \cos ^{4} \varphi, \\
& \bar{Q}_{66}=Q_{66}\left(\cos ^{4} \varphi+\sin ^{4} \varphi\right), \\
& \bar{Q}_{44}=Q_{44} \cos ^{2} \varphi+Q_{55} \sin ^{2} \varphi, \\
& \bar{Q}_{55}=Q_{55} \cos ^{2} \varphi+Q_{44} \sin ^{2} \varphi, \\
& \frac{v_{12}}{E_{1}}=\frac{v_{21}}{E_{2}}, \quad Q_{11}=\frac{E_{1}}{1-v_{12} v_{21}}, \\
& Q_{12}=\frac{v_{12} E_{2}}{1-v_{12} v_{21}}, \quad Q_{22}=\frac{E_{2}}{1-v_{12} v_{21}}, \\
& Q_{66}=G_{12}, \quad Q_{44}=G_{23}, \quad Q_{55}=G_{13},
\end{aligned}
$$

where $\varphi$ is the fiber angle of laminated shell. The principle of minimum potential energy shall be derived as follows:

$$
\delta\left(\widehat{U}-\widehat{W}_{s}-\widehat{W}_{e}\right)=0,
$$

in which $\widehat{U}$ is the strain energy, $\widehat{W}_{s}$ is the work of body and surface forces and $\widehat{W}_{e}$ is the work of external loading. These parameters are presented as:

$$
\begin{gathered}
\delta \widehat{U}=\int_{\theta} \int_{-\frac{L}{2}}^{\frac{L}{2}} \int_{\frac{h}{2}}^{\frac{h}{2}}\left(\sigma_{s} \delta \varepsilon_{s}+\sigma_{\theta} \delta \varepsilon_{\theta}+\sigma_{s \theta} \delta \gamma_{s \theta}\right. \\
\left.+\sigma_{s z} \delta \gamma_{s z}+\sigma_{\theta z} \delta \gamma_{\theta z}\right) R d \theta d s d z \\
\delta \widehat{W}_{s}=\int_{\theta} \int_{-L / 2}^{L / 2}\left(q_{s} \delta u+q_{\theta} \delta v-q_{z} \delta w\right) R d \theta d s \\
\widehat{W}_{e}=\frac{1}{2} \int_{\theta} \int_{-L / 2}^{L / 2} \frac{1}{2} \widehat{N}\left(\frac{\partial w}{\partial s}\right)^{2} R d \theta d s
\end{gathered}
$$

where $\widehat{N}$ is the in-plane compressive axial buckling force resultant. By integrating around the circumstances of one conical shell, the relation between the axial buckling load $\left(P_{c r}\right)$ and $\widehat{N}$ can be calculated as below:

$$
\widehat{N}=\frac{P_{c r}}{2 \pi R \cos \alpha} \text {. }
$$

By substituting the displacement field in straindisplacement and stress-strain relationships, the general form of equilibrium equations for each conical shell based on FSDT can be extracted in terms of $U(s, \theta), V(s, \theta), W(s, \theta), \beta_{s}(s, \theta)$ and $\beta_{\theta}(s, \theta)$ as follows:

$$
[L]\left\{U, V, W, \beta_{s}, \beta_{\theta}\right\}^{T}=\{q\} .
$$

$[L]$ is the matrix of the partial differential operators with partial derivatives with respect to $s$ and $\theta$, given in the Appendix. Additionally, using integration by parts, hereby, following is the extracted general form of boundary conditions:

$$
\begin{aligned}
& \int\left\{\left(N_{s}-\overline{N_{s}}\right) \delta u+\left(M_{s}-\overline{M_{s}}\right) \delta \beta_{s}+\left(N_{s \theta}-\overline{N_{s \theta}}\right) \delta v\right. \\
& \left.+\left(M_{s \theta}-\overline{M_{s \theta}}\right) \delta \beta_{\theta}+\left(Q_{s s}-\bar{Q}_{s s}\right) \delta w\right\} r d \theta .
\end{aligned}
$$

Upon this basis, various sets of boundary conditions were obtained from the above relationship, such as five boundary conditions at each end. Besides, at the interface of the two cones, displacements and forces would be equal; these continuity conditions ensure that all displacements and forces at the interface are equal; consequently, no distortion is possible at the interface (i.e., the connection is rigid).

Due to the satisfaction of the continuity constraint at the interface of the cones, relationships should be considered equally for the two cones in general and common coordinates. In this regard, the relationships for displacements and forces are equal along the cone's axis and normal to cone's axis then related to each other. Accordingly, continuity conditions at interface of the two shells are as follows.

$$
\begin{aligned}
& U_{1} \cos \alpha_{1}-W_{1} \sin \alpha_{1}=U_{2} \cos \alpha_{2}-W_{2} \sin \alpha_{2}, \\
& U_{1} \sin \alpha_{1}+W_{1} \cos \alpha_{1}=U_{2} \sin \alpha_{2}+W_{2} \cos \alpha_{2}, \\
& V_{1}=V_{2}, \quad \beta_{s 1}=\beta_{s 2}, \quad \beta_{\theta 1}=\beta_{\theta 2}, \\
& N_{s 1} \cos \alpha_{1}-Q_{s 1} \sin \alpha_{1}=N_{s 2} \cos \alpha_{2}-Q_{s 2} \sin \alpha_{2}, \\
& N_{s 1} \sin \alpha_{1}+Q_{s 1} \cos \alpha_{1}=N_{s 2} \sin \alpha_{2}+Q_{s 2} \cos \alpha_{2}, \\
& N_{s \theta 1}=N_{s \theta 2}, \quad M_{s 1}=M_{s 2}, \quad M_{s \theta 1}=M_{s \theta 2} .
\end{aligned}
$$




\section{SOLUTION METHOD}

To solve the extracted equations, firstly, the Fourier expansions were performed along the circumferential direction as follows:

$U(s, \theta)=\bar{u}(s) \cos n \theta, \quad V(s, \theta)=\bar{v}(s) \sin n \theta$,

$W(s, \theta)=\bar{w}(s) \cos n \theta$,

$\beta_{s}(s, \theta)=\overline{\beta_{s}}(s) \cos n \theta, \quad \beta_{\theta}(s, \theta)=\overline{\beta_{\theta}}(s) \sin n \theta$.

Secondly, the solution of the problem along $s$-axis was considered in terms of a power series (PS):

$\bar{u}(s)=\sum_{m=0}^{\infty} a_{m} s^{m}, \bar{v}(s)=\sum_{m=0}^{\infty} b_{m} s^{m}, \bar{w}(s)=\sum_{m=0}^{\infty} c_{m} s^{m}$,

$\overline{\beta_{s}}(s)=\sum_{m=0}^{\infty} d_{m} s^{m}, \quad \overline{\beta_{\theta}}(s)=\sum_{m=0}^{\infty} e_{m} s^{m}$.

Now, by substituting the above-mentioned series into Eq. (12) and sorting similar powers regarding $s$, one may end up with recursive relationships in terms of other coefficients. Using such relationships, one can obtain all constant coefficients in the series, except $a_{0}, a_{1}, b_{0}, b_{1}, c_{0}, c_{1}, d_{0}, d_{1}, e_{0}, e_{1}$ as well. Therefore, these 10 coefficients shall be derived by applying the boundary conditions and continuity constraints on the joined shells. The boundary conditions used in the present paper as the following forms:

Clamped(C): $u=v=w=\beta_{\theta}=\beta_{s}=0$,

Simply-Supported(S): $v=w=\beta_{\theta}=N_{s}=M_{s}=0,(17)$

Free(F): $N_{s}=M_{s}=N_{s \theta}=M_{s \theta}=Q_{s}=0$.

Evaluation of the above relationships for each conical shell under the boundary conditions and subject to the continuity conditions can be led to a system of 20 algebraic equations in terms of the coefficients of the series. By setting the determinant of coefficients matrix to zero, the value of critical buckling load for any given value of $n$ can be extracted. For this purpose, 30 terms of power series have been used.

\section{RESULTS AND DISCUSSION}

First, the dimensionless buckling parameters are presented in Table 1 for cross-ply cylindrical shells. If $\alpha_{1}$ and $\alpha_{2}$ are equal to zero, the conical shells change to cylinders. So, the buckling load of structure can be compared to the buckling load of cylinders in other researches. Hence, the results of the present study have been compared to Khdeir et al. [49] as well as
Shadmehri et al. [43] studies. In Table $1, L / R=1$, $h / R=0.1, \quad E_{1} / E_{2}=40, \quad v_{12}=0.25, \quad G_{23}=0.5 E_{2}$ and $G_{12}=G_{13}=0.6 E_{2}$ have been assumed as the geometric and material properties of cylindrical shells. The present results are in good agreement with other research results.

Table 1. Dimensionless critical buckling parameters

\begin{tabular}{|c|c|c|c|c|}
\hline \multirow{2}{*}{$B C$} & \multirow{2}{*}{$\begin{array}{l}\text { Lamination } \\
\text { sequences }\end{array}$} & $\begin{array}{c}\text { CST\& } \\
\text { Levy [49] }\end{array}$ & $\begin{array}{c}\text { FSDT\& } \\
\text { Levy [43] }\end{array}$ & $\begin{array}{c}\text { Present FSDT \& } \\
\text { Present study }\end{array}$ \\
\hline & & Single shell & Single shell & Joined Shells \\
\hline \multirow{2}{*}{ SS } & {$[0 / 90 / 0]$} & 0.2765 & 0.2813 & 0.2763 \\
\hline & {$[0 / 90]$} & 0.1525 & 0.1670 & 0.1629 \\
\hline \multirow{2}{*}{ CC } & {$[0 / 90 / 0]$} & 0.4168 & 0.4197 & 0.4145 \\
\hline & {$[0 / 90]$} & 0.2406 & 0.2508 & 0.2454 \\
\hline \multirow{2}{*}{ SC } & {$[0 / 90 / 0]$} & 0.3411 & 0.3452 & 0.3409 \\
\hline & {$[0 / 90]$} & 0.1851 & 0.1969 & 0.1923 \\
\hline
\end{tabular}

In continue, to come up with comparable results to other references, dimensionless buckling load is defined as follows:

$$
\bar{P}_{c r}=P_{c r} / P_{c y l o \infty},
$$

where $P_{c r}$ is critical buckling load, denotes dimensionless buckling load, and $P_{c y l \infty}$ is defined as follows [50]:

$$
P_{c y l \infty}=\frac{2 \pi E_{1} h^{2} \cos ^{2} \alpha}{\sqrt{3\left(1-v_{12}^{2}\right)}} .
$$

To undertake comparisons, the results of two joined cones at identical semi vertex-angles are compared to a single conical shell.

Tong and Wang [51], Abediokchi et al. [52] and Sharghi et al. [53], using Donnell-type shell theory, present a procedure for buckling analysis of laminated conical shells. The composite considered in those researches is an asymmetrically cross-ply laminated shell made from carbon/epoxy.

$$
\begin{gathered}
E_{2}=10 \mathrm{GPa}, \quad E_{1} / E_{2}=40, \\
v_{12}=0.25, \quad G_{12} / E_{2}=0.5 .
\end{gathered}
$$

The obtained results in Table 2 are for a constant thickness ratio of shells $(h / R=0.01)$ and different length of shells $(L / R)$, number of composite layers $\left(N_{L}\right)$ and semi-vertex angles $(\alpha)$, which falls within the scope of thin shells. The results are extracted for simply-supported boundary conditions at both ends. The results show a good agreement between the present and other results. 
Table 2. $\bar{P}_{c r}$ for S-S anti-symmetric laminated cross-ply conical shells $\left(h / R=0.01, \alpha=45^{\circ}\right)$

\begin{tabular}{|c|c|c|c|c|c|}
\hline \multirow{2}{*}{$L / R$} & \multirow{2}{*}{$N_{L}$} & $\begin{array}{c}\text { Tong and } \\
\text { Wang [51] }\end{array}$ & $\begin{array}{c}\text { Sharghi et } \\
\text { al. [53] }\end{array}$ & $\begin{array}{l}\text { Abediokchi } \\
\text { et al. [52] }\end{array}$ & $\begin{array}{l}\text { Present } \\
\text { study }\end{array}$ \\
\hline & & CST \& PS & CST \& PS & CST \& GDQ & FSDT \& PS \\
\hline \multirow{4}{*}{0.2} & 2 & $0.1146(8)$ & $0.1146(8)$ & $0.1146(8)$ & $0.1129(8)$ \\
\hline & 4 & $0.2488(7)$ & $0.2487(7)$ & $0.2488(7)$ & $0.2438(7)$ \\
\hline & 6 & $0.2732(7)$ & $0.2732(7)$ & $0.2733(7)$ & $0.2664(7)$ \\
\hline & $\infty$ & $0.2927(7)$ & $0.2927(7)$ & $0.2927(7)$ & $0.2857(7)$ \\
\hline \multirow{4}{*}{0.5} & 2 & $0.06751(6)$ & $0.06735(6)$ & $0.06734(6)$ & $0.06581(6)$ \\
\hline & 4 & $0.1054(6)$ & $0.1054(6)$ & $0.1053(6)$ & $0.1033(6)$ \\
\hline & 6 & $0.1117(5)$ & $0.1117(5)$ & $0.1117(5)$ & $0.1079(5)$ \\
\hline & $\infty$ & $0.1158(5)$ & $0.1158(5)$ & $0.1158(5)$ & $0.1129(5)$ \\
\hline \multirow{4}{*}{1} & 2 & $0.06743(6)$ & $0.06757(6)$ & $0.06748(6)$ & $0.06582(6)$ \\
\hline & 4 & $0.1063(5)$ & $0.1065(5)$ & $0.1064(5)$ & $0.1036(5)$ \\
\hline & 6 & $0.1122(5)$ & $0.1122(5)$ & $0.1121(5)$ & $0.1082(5)$ \\
\hline & $\infty$ & $0.1165(5)$ & $0.1165(5)$ & $0.1165(5)$ & $0.1118(5)$ \\
\hline
\end{tabular}

Table 3 demonstrates the results using FSDT by assuming identical thickness, length, and material for both cones. The non-dimensional critical buckling load of two joined cross-ply laminated conical shells is expressed for two orders of lamination sequences. As shown in Table 3, in all cases, the minimum values occurred when the lower shell is very similar to circular plate. The results illustrate that the order of lamination sequence is not very effective on the critical buckling load of joined asymmetrically crossply laminated shell. However, the use of $[90,0]$ lamination sequence obtains lower values than $[0,90]$.

Using the finite element (FE) and analytical methods, Table 3 presents the effects of the lamination stacking sequence on the critical buckling load of joined cross-ply laminated cones. The finite element modelling is implemented using the finite element method (FEM)-based software (ABAQUS/CAE). As an appropriate choice, a 4-nodes element with 24 degrees of freedom (DOFs) for each element (three rotational and three translational DOFs at each node) is used for FE analyses. This type of element reveals the effect of FSDT. Also, the effects of mesh refinement and mesh convergence on the FEM solution have been surveyed. The percentage differences shown in Table 4, expresses the difference between FEM and analytical solution results.

The results indicate an acceptable amount of difference of approximately $1.2561 \%$ to $1.8484 \%$. The effect of ordering of the layers on non-dimensional critical buckling load can be calculated with the following expression

$$
L S D=\frac{\bar{P}_{c r[90]}-\bar{P}_{c r}}{\bar{P}_{c r[90]}} \times 100 \%,
$$

where $L S D$ stands for lamination sequence differences. As is obvious from Table 4, the values of the axial buckling loads are minimum for the single-layer [0], whereas single layer [90] values are maximum. The impact of the lamination sequence on the critical axial load increases when the number of [90] layers grows, especially in outer layers.

Fig. 2 investigates the influence of changes in $\alpha_{1}$ on dimensionless buckling load.

Table 3. Non-dimensional buckling load $\left(\bar{P}_{c r}\right)$ for simply-supported laminated cross-ply conical shells $(L / R=0.1, h / R=0.1)$

\begin{tabular}{|c|c|c|c|c|c|c|c|}
\hline \multirow{3}{*}{$\alpha_{1}$} & \multirow{3}{*}{$\alpha_{2}$} & \multicolumn{3}{|c|}{$[0,90]$} & \multicolumn{3}{|c|}{$[90,0]$} \\
\hline & & \multicolumn{6}{|c|}{$N_{L}$} \\
\hline & & 2 & 4 & Sym. & 2 & 4 & Sym. \\
\hline \multirow{4}{*}{0} & 0 & 0.2697 & 0.3749 & 0.3109 & 0.2650 & 0.3714 & 0.4101 \\
\hline & 30 & 0.4030 & 1.0305 & 0.8455 & 0.3963 & 1.0217 & 1.1494 \\
\hline & 60 & 0.2863 & 0.6916 & 0.6527 & 0.2805 & 0.6801 & 0.7718 \\
\hline & 90 & 0.0049 & 0.0125 & 0.0167 & 0.0048 & 0.0124 & 0.0217 \\
\hline \multirow{4}{*}{30} & 0 & 0.4355 & 1.0593 & 0.8523 & 0.4324 & 1.0502 & 1.1506 \\
\hline & 30 & 0.2522 & 0.3507 & 0.2952 & 0.2438 & 0.3435 & 0.3805 \\
\hline & 60 & 0.2673 & 0.6689 & 0.5763 & 0.2634 & 0.6643 & 0.7350 \\
\hline & 90 & 0.0048 & 0.0126 & 0.0170 & 0.0047 & 0.0125 & 0.0221 \\
\hline \multirow{4}{*}{60} & 0 & 0.2970 & 0.6831 & 0.6163 & 0.2871 & 0.6757 & 0.7821 \\
\hline & 30 & 0.2715 & 0.6658 & 0.5410 & 0.2665 & 0.6519 & 0.7173 \\
\hline & 60 & 0.1216 & 0.1690 & 0.1456 & 0.1155 & 0.1651 & 0.1799 \\
\hline & 90 & 0.0047 & 0.0127 & 0.0171 & 0.0047 & 0.0126 & 0.0222 \\
\hline
\end{tabular}


Table 4. Effects of lamination sequences on $\bar{P}_{c r}$ for S-S crossply conical shells $\left(\alpha_{1}=30^{\circ}, \alpha_{2}=75^{\circ}, N_{L}=4, L / R_{1}=0.1\right.$, $\left.h / R_{1}=0.1\right)$

\begin{tabular}{ccccc}
\hline $\begin{array}{c}\text { Stacking } \\
\text { sequences }\end{array}$ & FEM & $\begin{array}{c}\text { Present } \\
\text { study }\end{array}$ & $\begin{array}{c}\text { Difference } \\
{[\%]}\end{array}$ & $\begin{array}{c}\text { LSD } \\
{[\%]}\end{array}$ \\
\hline$[0]$ & 0.3491 & 0.3440 & 1.4609 & 83.594 \\
\hline$[0 / 90 / 0]$ & 0.3787 & 0.3717 & 1.8484 & 82.273 \\
\hline$[0 / 0 / 90] S$ & 0.4086 & 0.4022 & 1.5663 & 80.818 \\
\hline$[0 / 90 / 0 / 90]$ & 0.4427 & 0.4363 & 1.4457 & 79.192 \\
\hline$[0 / 0 / 90 / 0]$ & 0.6774 & 0.6689 & 1.2548 & 68.099 \\
\hline$[0 / 0 / 90]$ & 0.7482 & 0.7357 & 1.6707 & 64.913 \\
\hline$[0 / 90 / 0] S$ & 0.8290 & 0.8178 & 1.3510 & 60.998 \\
\hline$[0 / 90 / 90] S$ & 0.8859 & 0.8720 & 1.5690 & 58.413 \\
\hline$[0 / 0 / 90 / 90]$ & 0.9076 & 0.8962 & 1.2561 & 57.259 \\
\hline$[0 / 90 / 90]$ & 1.1197 & 1.1001 & 1.7505 & 47.534 \\
\hline$[90 / 90 / 0]$ & 1.1318 & 1.1138 & 1.5904 & 46.881 \\
\hline$[90]$ & 2.1319 & 2.0968 & 1.6464 & - \\
\hline & & & &
\end{tabular}

As can be seen, with increasing the $\alpha_{2}$ angle from negative values toward zero (cylindrical shell), the value of buckling load goes up, and given the short length of the shells, critical buckling load decreases abruptly as semi-vertex angles of the two shells get closer to one another. In other words, a sharp decrease in buckling load occurs when the semi-vertex angles come close together. If two joined conical shells have the same semi-vertex angles, one cone could be shaped with a longer length. Accordingly, the buckling of the longer cone under axial compression occurs sooner and critical buckling load decreases. Furthermore, the minimum buckling load varies with semi-vertex angles. Increasing the semi-vertex angles decreases the minimum buckling load.

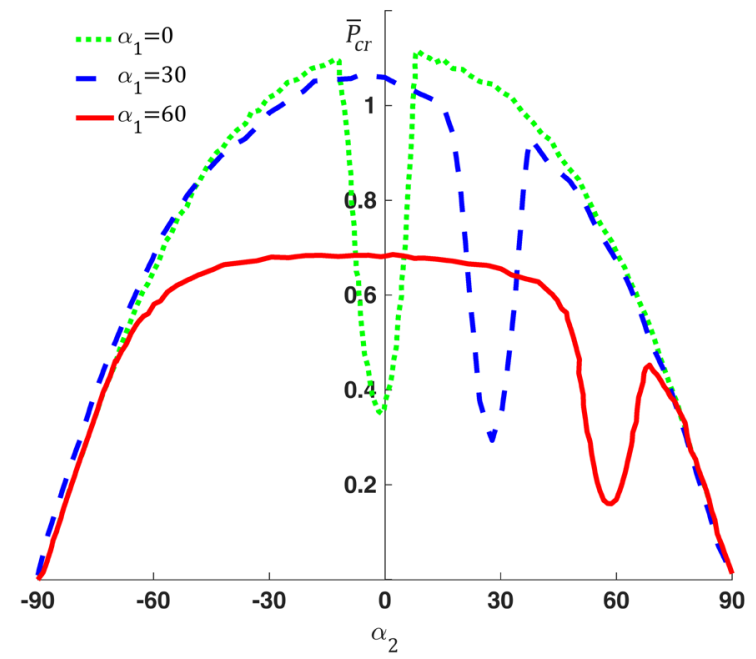

Fig. 2. Effect of changes in $\alpha_{l}$ on buckling load $\left(h / R_{1}=0.1\right.$,

$$
N_{L}=4, L / R_{1}=0.1 \text { ) }
$$

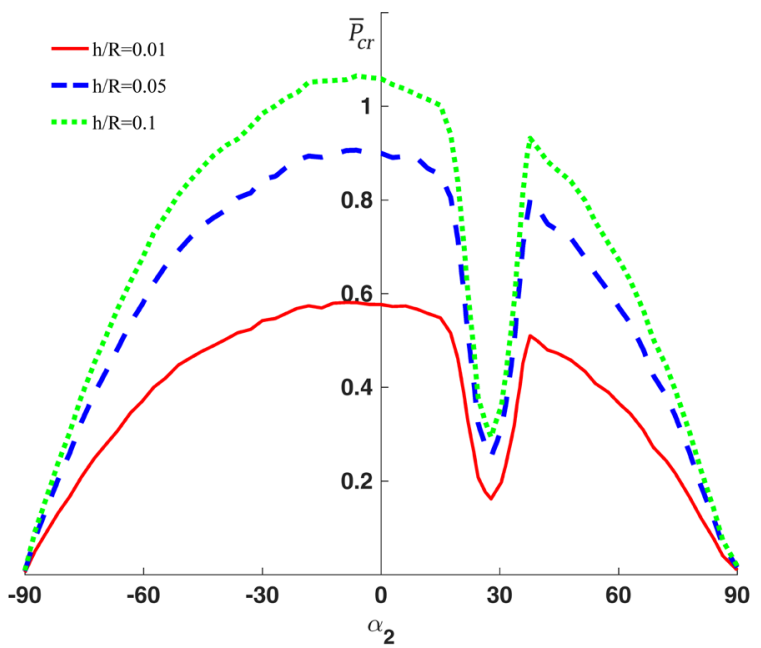

Fig. 3. Effect of changes in $h / R_{1}$ ratio on buckling load

$$
\left(\alpha_{1}=30^{\circ}, N_{L}=4, L / R_{1}=0.1\right)
$$

Fig. 3 demonstrate the effect of changes in $L / R_{1}$ ratio at different values of semi-vertex angle that considers a case where $\alpha_{1}=30^{\circ}, L / R_{1}=0.1$, and the number of layers is four. Upon increasing the $h / R_{1}$ ratio, the value of the dimensionless buckling load increases.

In Fig. 4, the effects of variations in $L / R_{1}$ on dimensionless buckling load have been shown.

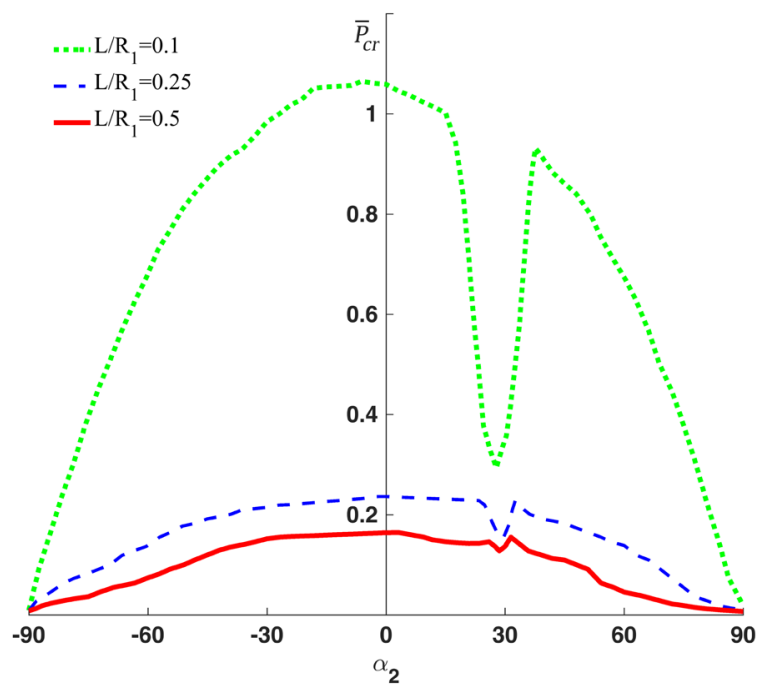

Fig. 4. Effect of changes in $L / R_{1}$ ratio on buckling load

$$
\left(\alpha_{1}=30^{\circ}, N_{L}=4, L / R_{1}=0.1\right)
$$

As mentioned before, in shorter shells, as semivertex angles of the two shells come closer to one another, a significant decrease occurs in buckling load; however, this rarely happens in longer shells. 
Fig. 5 presents the influence of changes in $N_{L}$ on a dimensionless buckling load. It is observed that the buckling load is very low in the case of being two layers. Due to the asymmetry of the shell at the low number of layers, it is rising by increasing the number of layers. Also, the minimum point changes by the number of layers and reaches to $\alpha_{2}$.

As shown in Fig. 6, for a special case, dimensionless buckling load was calculated for different thicknesses using classical shell theory (CST) of Donnell type based on the solution approach proposed by Shakoori and Kouchazadeh [31], and the obtained results were compared to those of the present research where FSDT was implemented.

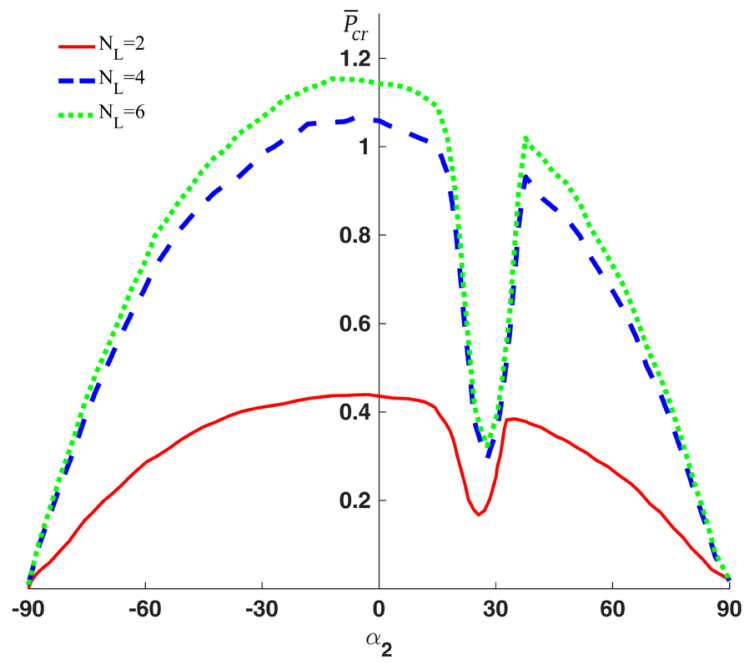

Fig. 5. Effect of changes in $N_{L}$ on buckling load $\left(h / R_{1}=0.1\right.$,

$$
\left.\alpha_{1}=30^{\circ}, L / R_{1}=0.1\right)
$$

As observed in Fig. 6, with increasing the thickness, the differences between classic theory and FSDT grow; i.e. the effects of shear force cannot be neglected, and the classic theory no longer provides acceptable results. The provoking point is that, in all cases, the results of FSDT are lower than those from the classic theory, and differences are presented even in the scope where the classic theory applies to thin shells $\left(h / R_{1} \leq 0.05\right)$, although those can be neglected adequately.

Fig. 7 presents the influence of boundary conditions on dimensionless buckling load. The value of dimensionless buckling load decreased as one moved from C-C, S-C, F-C and S-S to F-S state. The clamped condition at each end of shell raises the value of dimensionless buckling loads because of the increasing rigidity of the structure.

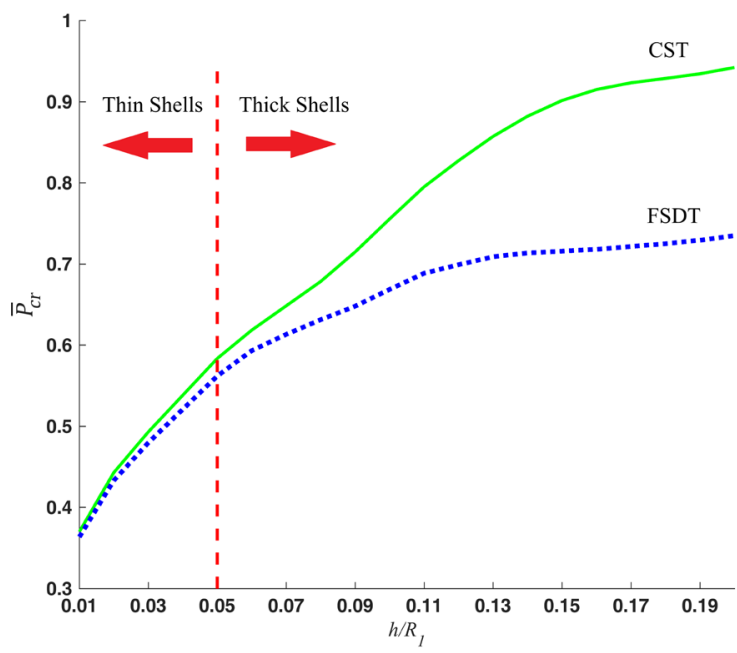

Fig. 6. Comparison between the results of classic theory and FSDT at different thicknesses

The results reveal that the value of $\bar{P}_{c r}$ in simply-supported conditions is slightly near to free conditions. In addition, it is necessary to explain that the critical buckling loads decrease abruptly when two joined conical shell have the same semi-vertex angles in all boundary conditions.

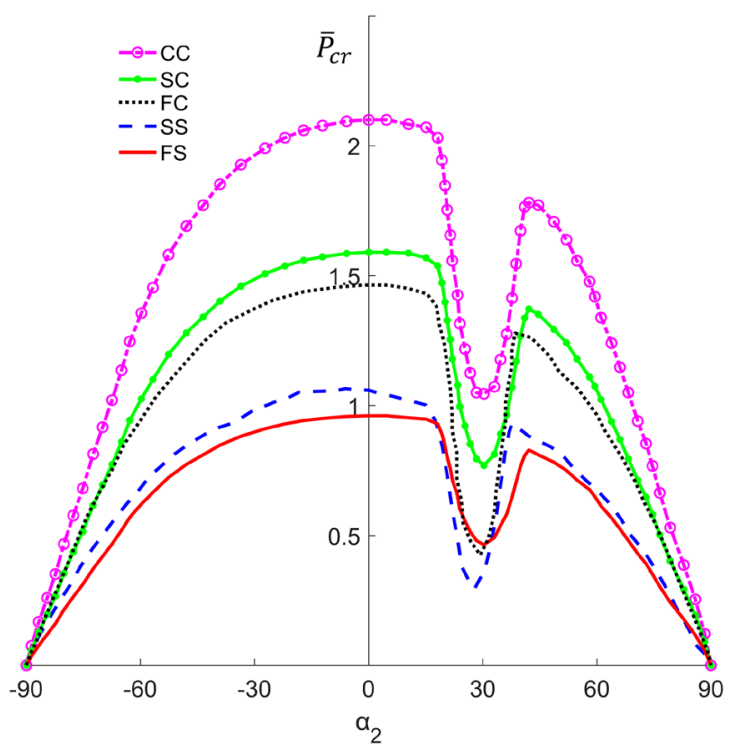

Fig. 7. Effect of boundary conditions on buckling load $\left(\alpha_{1}=30^{\circ}\right.$,

$$
\left.L / R_{1}=0.1, h / R_{1}=0.1\right)
$$

\section{CONCLUSIONS}

In this research, the buckling of two joined composite conical shells has been investigated using FSDT and CST, and the following general conclusions have been achieved. Effect of shear deformation is 
negligible in thin shells. In thick shells; however, the results will be considerably different from real values in which shear deformation is ignored.

In all cases, the results of FSDT are lower than those of classic theory, and differences are present even in the scope where the classic theory applies to thin shells $(h / R \leq 0.05)$, though those can be neglected adequately. Therefore, the usage of classic shell theory is not suggested in thick shells.

A sharp decrease in buckling load occurs where the semi-vertex angles come close together. In other words, in shorter shells, as semi-vertex angles of the two shells come closer to each other, buckling load decreases at a high rate. In conclusion, it is highly recommended to use two joined shells with appropriate semi-vertex angles instead of a single cone.

In thin shells, the highest rigidity of the structure occurs at nearly identical semi-vertex angles. However, in thicker shells, the rigidity of shells from thickness is more effective than semi-vertex angle of the shells resulted from geometry. Finally, the minimum buckling load occurs when the lower shell is very similar to plate.

\section{REFERENCES}

[1] Leissa, A.W. (1993). Vibration of shells. US Government Printing Office, Washington D.C., Acoustical Society of America, Originally issued by NASA 1973.

[2] Tani, J., Yamaki, N. (1970). Buckling of truncated conical shells under axial compression. AIAA Journal, vol. 8, no. 3, p. 568571, DOI:10.2514/3.5709.

[3] Tong, L. (1993). Free vibration of composite laminated conical shells. International Journal of Mechanical Sciences, vol. 35, no. 1, p. 47-61, D0l:10.1016/0020-7403(93)90064-2.

[4] Tong, L. (1993). Free vibration of orthotropic conical shells. International Journal of Mechanical Science, vol. 31, no. 5, p. 719-733, DOI:10.1016/0020-7225(93)90120-J.

[5] Wu, C.-P., Chiu, S.-J. (2002). Thermally induced dynamic instability of laminated composite conical shells. International Journal of Solids and Structures, vol. 39, no. 11, p. 30013021, DOI:10.1016/S0020-7683(02)00234-2.

[6] Civalek, Ö. (2005). Geometrically nonlinear dynamic analysis of doubly curved isotropic shells resting on elastic foundation by a combination of harmonic differential quadrature-finite difference methods. International Journal of Pressure Vessels and Piping, vol. 82, no. 6, p. 470-479, D0l:10.1016/j. ijpvp.2004.12.003.

[7] Civalek, O., Ulker M. (2005). HDQ-FD integrated methodology for nonlinear static and dynamic response of doubly curved shallow shells. Structural Engineering and Mechanics, vol. 19, no. 5, p. 535-550, Dol:10.12989/sem.2005.19.5.535.

[8] Viswanathan, K.K., Aziz, Z.A., Javed, S., Yaacob, Y., Pullepu, B. (2015). Free vibration of symmetric angle ply truncated conical shells under different boundary conditions using spline method. Journal of Mechanical Science and Technology, vol. 29, no. 5, p. 2073-2080, D0l:10.1007/s12206-015-0428-z.

[9] Sofiyev, A.H. (2004). The stability of functionally graded truncated conical shells subjected to aperiodic impulsive loading. International Journal of Solids and Structures, vol. 41, no. 13, p. 3411-3424, D0l:10.1016/j.jjsolstr.2004.02.003.

[10] Sofiyev, A.H., Zerin, Z., Korkmaz, A. (2008). The stability of a thin three-layered composite truncated conical shell containing an FGM layer subjected to non-uniform lateral pressure. Composite Structures, vol. 85, no. 2, p. 105-115, DOI:10.1016/j.compstruct.2007.10.022.

[11] Sofiyev, A.H., Alizada, A.N., Akin, Ö., Valiyev, A., Avcar, M., Adiguzel, S. (2012). On the stability of FGM shells subjected to combined loads with different edge conditions and resting on elastic foundations. Acta Mechanica, vol. 223, no. 1, p. 189204, D0I:10.1007/s00707-011-0548-1.

[12] Spagnoli, A. (2001). Different buckling modes in axially stiffened conical shells. Engineering Structures, vol. 23, no. 8, p. 957-965, DOI:10.1016/S0141-0296(00)00112-7.

[13] Spagnoli, A. (2003). Koiter circles in the buckling of axially compressed conical shells. International Journal of Solids and Structures, vol. 40, no. 22, p. 6095-6109, Dol:10.1016/ s0020-7683(03)00369-x.

[14] Ross, C.T.F., Sawkins, D., Johns, T. (1999). Inelastic buckling of thick-walled circular conical shells under external hydrostatic pressure. Ocean Engineering, vol. 26, no. 12, p. 1297-1310, DOl:10.1016/S0029-8018(98)00066-3.

[15] Ross, C.T.F., Little, A.P.F., Adeniyi, K.A. (2005). Plastic buckling of ring-stiffened conical shells under external hydrostatic pressure. Ocean Engineering, vol. 32, no. 1, p. 21-36, DOl:10.1016/j.oceaneng.2004.05.007.

[16] Hu, W.C.L., Raney, J.P. (1976). Experimental and analytical study of vibrations of joined Shells. AlAA Journal, vol. 5, no. 5, p. 976-980, DOl:10.2514/3.4111.

[17] Rose, J.L., Mortimer, R.W., Blum, A. (1973). Elastic-wave propagation in a joined cylindrical-conical-cylindrical shell. Experimental Mechanics, vol. 13, no. 4, p. 150-156, D0l:10.1007/BF02322668.

[18] Irie, T., Yamada, G., Muramoto, Y. (1984). Free vibration of joined conical-cylindrical shells. Journal of Sound and Vibration, vol. 95, no. 1, p. 31-9, D0l:10.1016/0022460X(84)90256-6.

[19] Tavakoli, M.S., Singh, R. (1989). Eigen solutions of joined/ hermetic shell structures using the state space method. Journal of Sound and Vibration, vol. 130, no. 1, p. 97-123, DOI:10.1016/0022-460X(89)90522-1.

[20] Flores, F.G., Godoy, L.A. (1991). Post buckling of elastic conecylinder and sphere-cylinder complex shells. International Journal of Pressure Vessels and Piping, vol. 45, no. 2, p. 237 258, D0l:10.1016/0308-0161(91)90095-J.

[21] Zhao, Y., Teng, J.G. (2003). A stability design proposal for conecylinder intersections under internal pressure. International Journal of Pressure Vessels and Piping, vol. 80, no. 5, p. 297 309, D0I:10.1016/S0308-0161(03)00048-6.

[22] Teng, J.G. (1996). Elastic buckling of cone-cylinder intersection under localized circumferential compression. Engineering Structures, vol. 18, no. 1, p. 41-48, Dol:10.1016/01410296(95)00114-3. 
[23] Teng, J.G., Barbagallo, M. (1997). Shell restraint to ring buckling at cone-cylinder intersections. Engineering Structures, vol. 19, no. 6, p. 425-431, D0l:10.1016/S01410296(96)00087-9.

[24] Teng, J.G., Ma, H.W. (1999). Elastic buckling of ringstiffened cone-cylinder intersections under internal pressure. International Journal of Mechanical Sciences, vol. 41, no. 11, p. 1357-1383, DOI:10.1016/S0020-7403(98)00097-6.

[25] Benjeddou, A. (2000). Vibration of complex shells of revolution using B-spline finite elements. Computers and Structures, vol. 74, no. 4, p. 429-440, Dol:10.1016/S0045-7949(99)00060-7.

[26] Kamat, S., Ganapathi, M., Patel, B.P. (2001). Analysis of parametrically excited laminated composite jointed conicalcylindrical shells. Computers and Structures, vol. 79, no. 1, p. 65-76, DOI:10.1016/S0045-7949(00)00111-5.

[27] Zhao, Y. (2005). Buckling behavior of imperfect ringstiffened cone-cylinder intersections under internal pressure. International Journal of Pressure Vessels and Piping, vol. 82, no. 7, p. 553-564, D0l:10.1016/J.ijpvp.2005.01.008.

[28] Caresta, M., Kessissoglou, N.J. (2010). Free vibrational characteristics of isotropic coupled cylindrical-conical shells. Journal of Sound and Vibration, vol. 329, no. 6, p. 733-751, D0I:10.1016/j.jsv.2009.10.003.

[29] Niloufari, A., Showkati, H., Maali, M., Mahdi Fatemi S. (2014). Experimental investigation on the effect of geometric imperfections on the buckling and post buckling behavior of steel tanks under hydrostatic pressure. Thin-Walled Structures, vol. 74 p. 59-69, D0l:10.1016/j.tws.2013.09.005.

[30] Ma, X., Jin, G., Xiong, Y., Liu, Z. (2014). Free and forced vibration analysis of coupled conical-cylindrical shells with arbitrary boundary conditions. International Journal of Mechanical Sciences, vol. 88, p. 122-137, D0l:10.1016/j. ijmecsci.2014.08.002.

[31] Spagnoli, A., Chryssanthopoulos, M.K. (1999). Elastic buckling and postbuckling behaviour of widely-stiffened conical shells under axial compression. Engineering Structures, vol. 21, no. 9, p. 845-855, D0l:10.1016/S0141-0296(98)00036-4.

[32] Rezaiee-Pajand, M., Arabi, E., Masoodi, A.R. (2018). A triangular shell element for geometrically nonlinear analysis. Acta Mechanica, vol. 229, no. 1, p. 323-342, Dol:10.1007/ s00707-017-1971-8.

[33] Rezaiee-Pajand, M., Masoodi, A.R., Arabi, E. (2018). On the shell thickness-stretching effects using seven-parameter triangular element. European Journal of Computational Mechanics, vol. 27, no. 2, p. 163-185, Dol:10.1080/177971 79.2018.1484208.

[34] Rezaiee-Pajand M., Arabi E., Masoodi A.R. (2019). Nonlinear analysis of FG-sandwich plates and shells. Aerospace Science and Technology, vol. 87, p. 178-189, D0l:10.1016/j. ast.2019.02.017.

[35] Bucalem M.L., Bathe, K.J., (1993). Higher-order MITC general shell elements. Numerical Methods in Engineering, vol. 36, no. 21, p. 3729-3754, D0l:10.1002/nme.1620362109.

[36] Bathe, K.J., Dvorkin, E.N. (1986). A formulation of general shell elements-the use of mixed interpolation of tensorial components. Numerical Methods in Engineering, vol. 22, no. 3, p. 697-722, Dol:10.1002/nme.1620220312.
[37] Petrolo, M., Carrera, E. (2019). Best theory diagrams for shell finite elements. AIAA SciTech Forum, D0I:10.2514/6.20191765.

[38] Li, G., Carrera, E., Cinefra, M., de Miguel, A.G., Pagani, A., Zappino, E. (2019). An adaptable refinement approach for shell finite element models based on node-dependent kinematics. Composite Structures, vol. 210, p. 1-19, DOl:10.1016/j.compstruct.2018.10.111.

[39] Schuß, S., Dittmann, M., Wohlmuth, B., Klinkel, S., Hesch, C. (2019). Multi-patch isogeometric analysis for Kirchhoff-Love shell elements. Computer Methods in Applied Mechanics and Engineering, vol. 349, p. 91-116, Dol:10.1016/j. cma.2019.02.015.

[40] Shakouri, M., Kouchakzadeh, M.A. (2013). Stability analysis of joined isotropic conical shells under axial compression. Thin-Walled Structures, vol. 72, p. 20-27, D0l:10.1016/j. tws.2013.06.012.

[41] Kouchakzadeh, M.A., Shakouri, M. (2015). Analytical solution for axisymmetric buckling of joined conical shells under axial compression. Structural Engineering and Mechanics, vol. 54, no. 4, p. 649-664, D0I:10.12989/sem.2015.54.4.649.

[42] Shakouri, M., Kouchakzadeh, M.A. (2014). Free vibration analysis of joined conical shells: Analytical and experimental study. Thin-Walled Structures, vol. 85, p. 350-358, D0l:10.1016/j.tws.2014.08.022.

[43] Shadmehri, F., Hoa, S.V., Hojjati, M. (2012). Buckling of conical composite shells. Composite Structures, vol. 94, no. 2, p. 787 792, D0I:10.1016/j.compstruct.2011.09.016.

[44] Shadmehri, F., Hoa, S.V., Hojjati, M. (2014). The effect of displacement field on bending, buckling, and vibration of cross-ply circular cylindrical shells. Mechanics of Advanced Materials and Structures, vol. 21, no. 1, p. 14-22, Dol:10.1080 /15376494.2012.677102.

[45] Sarkheil, S., Foumani, M.S., Navazi, H.M. (2016). Theoretical and experimental analysis of the free vibrations of a shell made of $n$ cone segments joined together. Thin-Walled Structures, vol. 108, p. 416-427, D0l:10.1016/j.tws.2016.08.022.

[46] Sarkheil, S., Foumani, M.S., Navazi, H.M. (2017). Free vibrations of a rotating shell made of $p$ joined cones. International Journal of Mechanical Sciences, vol. 124-125 p. 83-94, D0l:10.1016/j.ijmecsci.2017.02.003.

[47] Izadi, M.H., Hosseini-Hashemi, S., Korayem, M.H. (2018). Analytical and FEM solutions for free vibration of joined crossply laminated thick conical shells using shear deformation theory. Archive of Applied Mechanics, vol. 88, no. 12, p. 22312246, D0I:10.1007/s00419-018-1446-y.

[48] Reddy, J.N. (2004). Mechanics of Laminated Composite Plates and Shells: Theory and Analysis, CRC Press, Boca Raton.

[49] Khdeir A.A., Reddy, J.N., Frederick, D. (1989). A study of bending, vibration and buckling of cross-ply circular cylindrical shells with various shell theories. International Journal of Engineering Science, vol. 27, no. 11, p. 1337-1351, DOI:10.1016/0020-7225(89)90058-X.

[50] Seide, P. (1956). Axisymmetrical buckling of circular cones under axial compression. Journal of Applied Mechanics, vol. 23, no. 4, p. 625-628.

[51] Tong, L., Wang, T.K. (1992). Simple solutions for buckling of laminated conical shells. International Journal of Mechanical 
Sciences, vol. 34, no. 2, p. 93-111, D0l:10.1016/00207403(92)90076-S.

[52] Abediokhchi, J., Kouchakzadeh, M.A., Shakouri, M. (2013). Buckling analysis of cross-ply laminated conical panels using GDQ method. Composites Part B: Engineering, vol. 55, p. 440446, D0l:10.1016/j.compositesb.2013.07.003.

[53] Sharghi, H., Shakouri, M., Kouchakzadeh, M.A. (2016). An analytical approach for buckling analysis of generally laminated conical shells under axial compression. Acta Mechanica, vol. 227, no. 4, p. 1181-1198, D0l:10.1007/ s00707-015-1549-2.

\section{APPENDIX}

The partial differential operators:

$$
\begin{aligned}
& L_{11}=A_{11} \partial_{s s}+\frac{A_{11} \sin \alpha}{R(s)} \partial_{s}-\frac{A_{22} \sin ^{2} \alpha}{R^{2}(s)}+\frac{A_{33}}{R^{2}} \partial_{\theta \theta}, \\
& L_{12}=\frac{A_{12}+A_{33}}{R(s)} \partial_{s \theta}-\frac{\left(A_{22}+A_{33}\right) \sin \alpha}{R^{2}(s)} \partial_{\theta} \text {, } \\
& L_{13}=\frac{A_{12} \cos \alpha}{R(s)} \partial_{s}-\frac{A_{22} \sin \alpha \cos \alpha}{R^{2}(s)}, \\
& L_{14}=B_{11} \partial_{s s}+\frac{B_{11} \sin \alpha}{R(s)} \partial_{s}-\frac{B_{22} \sin ^{2} \alpha}{R^{2}(s)}+\frac{B_{33}}{R^{2}} \partial_{\theta \theta} \text {, } \\
& L_{15}=\frac{\left(B_{12}+B_{33}\right)}{R(s)} \partial_{s \theta}-\frac{\left(B_{22}+B_{33}\right) \sin \alpha}{R^{2}(s)} \partial_{\theta}, \\
& L_{21}=\frac{\left(A_{12}+A_{33}\right)}{R(s)} \partial_{s \theta}+\frac{\left(A_{22}+A_{33}\right) \sin \alpha}{R^{2}(s)} \partial_{\theta} \text {, } \\
& L_{22}=A_{33}\left[\partial_{s s}+\frac{\sin \alpha}{R(s)} \partial_{s}-\frac{\sin ^{2} \alpha}{R^{2}(s)}\right] \\
& +\frac{A_{22}}{R^{2}(s)} \partial_{\theta \theta}-\frac{A_{44} \cos ^{2} \alpha}{R^{2}(s)}, \\
& L_{23}=\frac{\left(A_{22}+A_{44}\right) \cos \alpha}{R^{2}(s)} \partial_{\theta}, \\
& L_{24}=\frac{\left(B_{12}+B_{33}\right)}{R(s)} \partial_{s \theta}+\frac{\left(B_{22}+B_{33}\right) \sin \alpha}{R^{2}(s)} \partial_{\theta} \text {, } \\
& L_{25}=B_{33}\left[\partial_{s s}+\frac{\sin \alpha}{R(s)} \partial_{s}-\frac{\sin ^{2} \alpha}{R^{2}(s)}\right] \\
& +\frac{B_{22}}{R^{2}(s)} \partial_{\theta \theta}+\frac{A_{44} \cos \alpha}{R(s)},
\end{aligned}
$$

$$
\begin{aligned}
L_{31} & =-\frac{A_{12} \cos \alpha}{R(s)} \partial_{s}-\frac{A_{22} \sin \alpha \cos \alpha}{R^{2}(s)}, \\
L_{32} & =-\frac{\left(A_{22}+A_{44}\right) \cos \alpha}{R^{2}(s)} \partial_{\theta}, \\
L_{33} & =A_{55}\left[\partial_{s s}+\frac{\sin \alpha}{R(s)} \partial_{s}\right]+\frac{A_{44}}{R^{2}(s)} \partial_{\theta \theta}-\frac{A_{22} \cos ^{2} \alpha}{R^{2}(s)} \\
& +\frac{P_{c r}}{2 \pi R(s) \cos \alpha} \partial_{s s},
\end{aligned}
$$$$
L_{34}=\left(A_{55}-\frac{B_{12} \cos \alpha}{R(s)}\right) \partial_{s}+\frac{A_{55} \sin \alpha}{R(s)}-\frac{B_{22} \sin \alpha \cos \alpha}{R^{2}(s)},
$$$$
L_{35}=\left(\frac{A_{44}}{R(s)}-\frac{B_{22} \cos \alpha}{R^{2}(s)}\right) \partial_{\theta},
$$$$
L_{41}=B_{11} \partial_{s s}+\frac{B_{11} \sin \alpha}{R(s)} \partial_{s}-\frac{B_{22} \sin ^{2} \alpha}{R^{2}(s)}+\frac{B_{33}}{R^{2}(s)} \partial_{\theta \theta},
$$$$
L_{42}=\frac{\left(B_{12}+B_{33}\right)}{R(s)} \partial_{s \theta}-\frac{\left(B_{22}+B_{33}\right) \sin \alpha}{R^{2}(s)} \partial_{\theta},
$$$$
L_{43}=-\left(A_{55}-\frac{B_{12} \cos \alpha}{R(s)}\right) \partial_{s}-\frac{B_{22} \sin \alpha \cos \alpha}{R^{2}(s)},
$$$$
L_{44}=D_{11} \partial_{s s}+\frac{D_{11} \sin \alpha}{R(s)} \partial_{s}-\frac{D_{22} \sin ^{2} \alpha}{R^{2}(s)}+\frac{D_{33}}{R^{2}(s)} \partial_{\theta \theta}-A_{55},
$$$$
L_{45}=\frac{\left(D_{12}+D_{33}\right)}{R(s)} \partial_{s \theta}-\frac{\left(D_{22}+D_{33}\right) \sin \alpha}{R^{2}(s)} \partial_{\theta},
$$$$
L_{51}=\frac{\left(B_{12}+B_{33}\right)}{R(s)} \partial_{s \theta}+\frac{\left(B_{22}+B_{33}\right) \sin \alpha}{R^{2}(s)} \partial_{\theta}
$$$$
L_{52}=B_{33}\left[\partial_{s s}+\frac{\sin \alpha}{R(s)} \partial_{s}-\frac{\sin ^{2} \alpha}{R^{2}(s)}\right]+\frac{B_{22}}{R^{2}(s)} \partial_{\theta \theta}
$$$$
+\frac{A_{44} \cos \alpha}{R(s)}
$$$$
L_{53}=-\left(\frac{A_{44}}{R(s)}-\frac{B_{22} \cos \alpha}{R^{2}(s)}\right) \partial_{\theta}
$$$$
L_{54}=\frac{\left(D_{12}+D_{33}\right)}{R(s)} \partial_{s \theta}+\frac{\left(D_{22}+D_{33}\right) \sin \alpha}{R^{2}(s)} \partial_{\theta},
$$$$
L_{55}=D_{33}\left[\partial_{s s}+\frac{\sin \alpha}{R(s)} \partial_{s}-\frac{\sin ^{2} \alpha}{R^{2}(s)}\right]+\frac{D_{22}}{R^{2}(s)} \partial_{\theta \theta}-A_{44} .
$$ 